the horizon of the initial velocity of translation) must be comparable with $45^{\circ}$.

The uphill path is nearly straight until the forward velocity becomes small; the projectile then returns along a track close to that of the ascent (Figs. I 2 and I3).

Non-returning fights. - A good boomerang of the second type will travel an immense distance in a nearly straight line if properly thrown. The motion should resemble that of an aëroplane or flying machine; the plane of rotation must remain nearly horizontal though slightly uphill, and the trajectory must be flat. There will thus be an upward pressure of air on the under surface of the implement, and the force of gravity will be counteracted as long as there is sufficient forward velocity. The boomerang is thrown very slightly uphill, the angle of projection not being greater than $12^{\circ}$; the rounded side is uppermost and $\theta$ is initially $30^{\circ}$. The plane of rotation soon appears to the thrower to become approximately horizontal, and it remains so during the flight ; the projectile rises to a height of about $12 \mathrm{~m}$. from the ground and travels in a nearly straight path until its forward velocity is almost exhausted ; it then strikes the earth at a distance of about 130 metres from the thrower.

It will be seen that the angular velocity (I) is at first small and positive, and that it subsequently disappears; the angular velocity $(2)$ is small throughout. These results are due to the left-handed twist and the rounding.

Considerable accuracy both in making and in throwing is necessary if the best results are to be obtained. If the plane of rotation slopes downward to one side, the boomerang will slide down in the inclined plane of rotation; thus the path will be bent and materially shortened. The correct relation has to be found between the twist, the rounding, the angle between the arms of

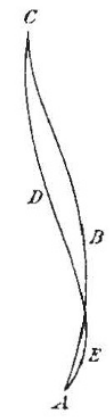

F1G. I2.-Plan.

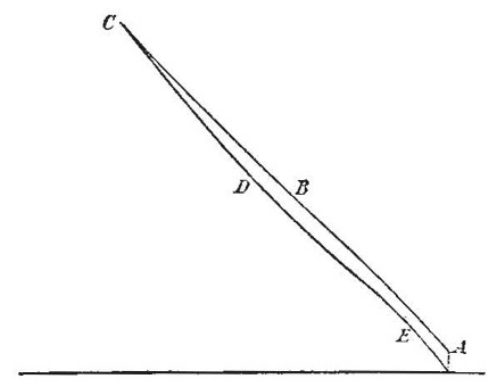

FIG. 13.-Elevation through A C.

the boomerang, the density of its material, and the amounts and directions of its initial linear and angular velocities. An illustration of this is afforded by the first specimen of this type that I have made; it travels further against the wind than with it. In the former case the boomerang keeps quite low, scarcely rising higher than 6 metres, and, being retarded very little by frictional resistance, travels about 125 metres ; in the latter case the body spends its energy in running uphill to a height of about I 5 metres, and falls to the ground at a distance of about 90 metres.

It is rather difficult to give sufficient spin to keep the motion stable through a long flight, and I have found it advantageous to wind round the wood about 60 grammes weight of copper wire in three equal portions, of which one is in the middle and one near each end. This materially increases the moment of inertia about the centre of gravity without interfering seriously with other details. I have thrown a loaded boomerang of this type 167 metres, and my range with a spherical ball of half the weight is only 63 metres.

Mode of manufacture.-A block of straight-grained ash about $90 \mathrm{~cm}$. long, $7 \mathrm{~cm}$. (or $7.5 \mathrm{~cm}$.) thick, and of width not less than $7 \mathrm{~cm}$. is taken. The block is soaked in steam, bent to the requisite shape and held in this shape until cool and dry. It is then sawn into strips $\mathrm{I}^{\cdot} 3 \mathrm{~cm}$. thick. After sufficient time has lapsed for the wood to be seasoned, each strip is trimmed into a boomerang, the most useful tool in general being a spokeshave. It is very important that the outer edge, at any rate in the neighbourhood of the bend, should follow the grain of the wood. When the projectile falls hard upon one end the stress near the centre is very severe, and any point at which the direction of NO. I 657, vOL. 64] the grain meets the convex edge obliquely is likely to develop a split and ultimately a breakage.

It is better to cut the material to its final twisted shape rather than to impart the twist by another steaming and bending. Considerable care is required in the process, for the removal of a layer of wood a millimetre thick in such a way as to increase or diminish the twist will cause a marked difference in the flight. It will be found to facilitate throwing to cut that end of the boomerang which is held in the hand to the somewhat square form shown at the right hand of Figs. I and 3 .

There is some difficulty in avoiding warping, for boomerangs are less likely to get broken if thrown when the ground is damp and soft, and under these circumstances the moisture is likely to be absorbed by the wood. It is of great advantage, therefore, to make the surface of the implements very smooth with fine glass-paper and to saturate them with linseed oil. The additional density thereby produced is also of service in that it diminishes the effect of the frictional resistance of the air.

I have used artificially bent oak as a material, but have not found it as heavy or as strong as ash. Oak branches that are naturally bent are not hard to procure, but boomerangs made from them are liable to break at places where there are knots or irregularities in the grain of the wood.

Evolution.-Boomerangs of every variety of shape are still to be found in Australia, and it appears impossible to get direct historical evidence as to the nature of the successive stages of development. But if speculation be allowed, the following series may be suggested.

First we should have a clumsy kind of wooden sword, curved, but without rounding or twist, and with one end roughened to form a handie; when the intended victim was out of reach it would be natural to throw the weapon, and at short ranges it would be extremely effective. Bad workmanship would involve the frequent production of implements of which one side was more rounded than the other, and it would soon be found that these missiles, when thrown with the rounded side uppermost, travelled much further and straighter than the former.

Boomerangs of this character vary in length from 50 to $\mathrm{I}$ Io $\mathrm{cm}$., and in weight from 200 grammes to 1250 . They are, for the most part, twisted in a manner that seems quite fortuitous, and form the enormous majority of the present native implements. Light specimens with a slight left-handed twist may have a fairly straight trajectory of 100 metres, and may return if aimed much uphill, especially when thrown against a wind. Those which are bent through a large enough angle and happen to be twisted (either by carelessness in manufacture or by subsequent warping ${ }^{1}$ ) after the manner of a right-handed screw are returning boomerangs of the first type. In many of these the twist is so large as to be conspicuous, and when once the connection between the form and the return flight has been noticed, the process of development is complete.

Gilbert T. Walker.

\section{THE INTERNATIONAL SEISMOLOGICAL CONFERENCE AT STRASSBURG.}

IN 1895 the late Dr. Rebeur-Paschwitz proposed, with the approval of Prof. Milne and other seismologists, to form an international seismological union. Although, unfortunately, he did not live to carry the project into execution, the microseismic survey of the world has since then been actively pushed on by Prof. Milne, the observatories using the Milne horizontal pendulums now numbering about forty. Meanwhile, the project of Rebeur-Paschwitz was taken up by Prof. Gerland, and, thanks to his active exertions, the first international seismological conference was finally held at Strassburg on April II13. The total number of the members who attended the.conference was thirty-five, as follows:-Austria-Hungary (Prof. Belar, Prof. Exner, Prof. von Kövesligethy, Hofrath Konkoly, Prof. Láska, Prof. Schafarzik); Belgizem (Prof. Langrange); Denmark (Lieutenant-Colonel Harboe); Germany (Dr. Ebell, Dr. Ehrismann, Prof. Futterer, Prof. Gerland, Prof. Guinther, Dr. Hecker, Prof. Helmert, Herr Jaehnike, Prof. Kobold, Geheimrath Lewald, Prof. Leutz, Prof. Rudolph, Dr. Polis, Prof. Schmidt, Dr. Schuitt, Prof. Straubel, Dr. Tetens, Prof. Wagner, Prof. Weigand, Yrof. Wiechert); Italy (Dr. Oddone); Japan

1 This may be illustrated by the fact that when the author first made boomerangs he was only aware of the need for rounding; but the first two specimens that he constructed happened to have right-handed twist and returned admirably. 
(Dr. Omori) ; Russia (General Pomerantzeff, Prof. Lewitzky, Dr. Wosnesjenskij) ; Szritzerland (Prof. Forel, Prof. Riggen. bach). Among these thirty-five members there were sixteen official delegates for the different States, as follows :-AustriaHungary, I ; Belgium, I ; Germany, 9 ; Japan, I ; Russia, 2 Switzerland, 2.

The principal object of the conference was the establishment of an international seismological union. After some discussion the projet of statutes of an "International Seismological Association," formed principally in imitation of the statutes of the International Catalogue Association and of the International Geodetic Association, was unanimously accepted by the conference, the chief points being as follows :-

$\& \mathrm{I}$. The object of the Association is the advancement of knowledge of all the seismological problems, which can be solved only by the cooperation of numerous seismological observatories all over the world. As the principal means of attaining this object are proposed :-(I) seismological observations according to fixed plans; (2) experiments on certain important seismological questions; (3) establishment and support of seismological stations in certain countries which need assistance from the Association; (4) organisation of a central bureau for collection and discussion of the reports from various countries.

§ 3. The parts of the Association are :-(I) general meeting ; (2) permanent commission; (3) central bureau.

\$5. The permanent commission consists of the director of the central bureau and of one member from each of the States which compose the Association. . .

$\S 8$. Each State must duly communicate to the central bureau, through its local central bureau, the results of seismic observations and experiments.

§ 9. Each State must contribute to the central bureau a certain yearly sum of money, to be fixed in proportion to the number of the inhabitants. The sum thus contributed by the different States is to be appropriated to the following purposes:-(I) publications and administration; (2) remuneration to the general secretary; (3) support of those who work in special important seismological investigations; (4) support of those seismological observatories which are established by the Association. The distribution of the sum into these various items is to be decided by the permanent commission.

As to the seismological observations, experiments and publications in the different States, the latter have a perfect freedom. The choice of the instruments is also left free to each State. The statutes of the Association having been thus adopted by the conference, the further steps for the formation of the Association are now to be taken by the Imperial German Government through diplomatic channels.

As there is still one year or so before the Association can be actually formed, it was proposed by Prof. Helmert to establish a provisionary central bureau and let the latter begin at once the function for the international seismological investigation, under the cooperation of all the members present, who approved the proposal and promised to send in publications and reports. Prof. Forel proposed, in the name of all the non-German members to select the Strassburg Seismulogical Observatory as the provisionary central bureau, under the direction of Prof. Geriand. This proposal was accepted, the Association being thus provisionally formed. Besides the establishment of the statutes, there were given by Prof. Helmert and others a series of valuable reports and lectures on observational as well as theoretical seismology.

The first international seismological conference proved to be a very satisfactory one. The full minutes of the transactions are expected to be published shortly.

F. OMORI

\section{UNIVERSITY AND EDUCATIONAL INTELLIGENCE.}

DR. R. T. HewletT, of the Jenner Institute of Preventive Medicine, has been appointed professor of general pathology and bacteriology at King's College, London.

THE following candidates have passed the D.Sc. examination of the University of London:-Mathematics and Physics, J. Buchanan; Experimental Physics, C. V. Drysdale, W. H. Eccles, P. E. Shaw ; Chemistry, T. J. Baker, T. A. Henry, W. H. Hurtley, G. D. Lander, H. R. Le Sueur, S. Smiles.

$$
\text { NO. I657, vOL. 64] }
$$

THE following regulation from the new Calendar of the Imperial University at Kyoto show that the Japanese are encouraging scientific research among University students :- "In Tune and December every year each student shall report to the director of the College, through his professor, the state and progress of research which he has made in his study of special subject ; and the director shall submit such report to the Faculty meeting for examination. When a student has completed the work of research at the University Hall, he shall prepare a record of his career at the University and present it to the president of the University, through his professor." Progress is bound to be made where education is carried on in this spirit.

\section{SCIENTIFIC SERIAL}

Bulletin of the American Mathematical Society, July.Surfaces whose first and second fundamental forms are the second and first respectively of another surface, by Dr. Eisenhart, was read at the February meeting. The results arrived at are-the ruled surfaces, defined by the equations

$$
\begin{gathered}
y+\mu x=\sqrt{\mathrm{I}+\mu^{2}}+\mathrm{C}_{1} \mu+\mathrm{C}_{1} \\
z-i x \sqrt{\mathrm{I}+\mu^{2}}=\mu+\mathrm{C}_{1} \sqrt{1+\mu^{2}}+\mathrm{C}_{3},
\end{gathered}
$$

are the only surfaces whose first and second fundamental forms can be taken for the second and first fundamental forms of a surface. Further, the second surface is only the first to a translation près. And of these surfaces the only real one is the sphere of radius unity-the C's, as usual, are arbitrary constants. References are given to work by Bianchi, Casorati, Monge and Forsyth.-On the groups generated by two operators, by Dr. G. A. Miller, was read at the April meeting. This short note, which gives several references, discusses the theorem, "every group that is generated by two operators of order two is a dihedral rotation group, and every dihedral rotation group is generated by two operators of order two."-Mr. G. Peirce gives a curious approximate construction for $\pi$, read at the same meeting. This is as neat a construction as we can remember. - Non-Euclidean geometry is a short notice, by J. L. Coolidge, of a work with this title by Dr. H. P. Manning.-J. K. Whittemore gives an extended abstract of "Vorlesungen über Differential geometrie "(pp. xvi +659), a transiation of Bianchi's work by M. Lukat. - Notes, new publications, tenth annual list of papers (read before the Society, with references to their places of publication), and a full index close the number and the volume.

\section{SOCIETIES AND ACADEMIES.}

\section{LONDON.}

Royal Society, June 20.- " Further Observations on Nova Persei. No. 3." By Sir Norman Lockyer, K.C.B., F.R.S.

In a former paper an account was given of the observations of the Nova, made at Kensington between March 5 and March 25 inclusive. The observations are now brought up to midnight of May 7. Between March 25 and the latter date, estimates of the magnitude of the Nova have been made on thirty-three evenings, visual observations of the spectrum on twenty-five evenings, and photographs of the spectrum on six evenings.

The Io-inch refractor with a McClean spectroscope has generally been used for eye observations. The 6-inch prismatic camera has not been available for photographing the spectrum owing to the faintness of the Nova, but photographs have been secured by Dr. Lockyer with the 30 -inch reflector on the nights of March 27, April I and I2, and by Mr. Fowler on March 26 and April 4. With the 9-inch prismatic reflector the spectrum was photographed by Mr. Hodgson on March 30, April I and 4 .

Change of Brightness. - Since March 25 the magnitude of the Nova has been undergoing further periodic variations, and although observations have not been made on every night since that date, owing to unfavourable weather, yet sufficient data have been gathered to enable a general idea of the light changes to be obtained, and the few gaps can be filled up later by other observers who experienced clearer skies on these occasions.

A table is given containing observations for magnitude made from March 26 to May 5 inclusive. 